\title{
The Construction and Reconstruction of Practical Aesthetics Discourse System in the Past 40 Years Since Economic Reform and Open up
}

\author{
Wei Wang \\ Quanzhou Normal University \\ Quanzhou, China
}

\begin{abstract}
Practical aesthetics is closely related to the enlightenment thought in the new era, which embodies the efforts of Chinese scholars to try to tell stories of China to the world in an aesthetic way. Post-practice aesthetics talks with the world on the basis of rethinking the modernity and participates in the construction of a new global aesthetic order, thus providing ideological resources for the construction of literary aesthetics in the new era.
\end{abstract}

Keywords-practical aesthetics; aesthetic experience; artistic aesthetics

\section{INTRODUCTION}

As the saying goes, "all academic issues are responses to the times". The aesthetics that has a large "academic population" in China and once occupied the center of academic discourse is no exception, and even more obvious. Specific to the contemporary aesthetics, the practical aesthetics represented by Li Zehou, truly reflects that the humanistic intellectuals are trying to open the world in a unique way of aesthetics under the guidance of historical consciousness, and are trying to tell Chinese stories, express Chinese experience, and contribute Chinese wisdom to the people in the vivid language of aesthetics. Needless to avoid mentioning that we need to summarize and carefully sort out in time the results of this effort and its significance and impact on the construction of the discipline itself and the construction of public space. In view of this, in recent years, many scholars have conducted a series of excellent discussions on the historical context, reality extension and future development of practical aesthetics on the impulse of "rewriting the history of aesthetics" and "rewriting the history of contemporary art", based on their different coordinates, and according to different evaluation criteria. These discussions have not only become important growth points for the production of theoretical knowledge of contemporary aesthetics and art, but also promoted the maturity of Chinese aesthetics and its participation in the reorganization of the world's aesthetic discourse order. The discussions themselves have also become an important component of the history of Chinese aesthetics and even the history of world aesthetics.

This article puts practical aesthetics in the background of the historical process of modernity in China, adopts the overall examination method of the combination of academic history and social history, and discusses the linkage and interaction between the practical aesthetics and the spirit of the times in the dialectic of internal and external perspectives. Through research, we hope to solve the following problems: First, how does practical aesthetics construct the discourse system of Chinese aesthetics in the process of dialogue with other aesthetic schools of thought? Second, "why" and "how" was the practical aesthetics described by contemporary estheticians as an important product and concrete embodiment of the ideological liberation movement in the 1980s and to provide supporting awareness for the "New Enlightenment" ? Third, how does the practical aesthetics with the elitist tendency explain the era of "post-enlightenment" which is populist and entertaining? In short, I hope to achieve the following goals through the study of the above related problems in this paper: First, explore how Chinese aesthetics can make its own discourse system innovate and rewrite the research pattern of world aesthetics through the mainstream school of thought of practical aesthetics. Second, look forward to the historical mission and realistic responsibility of Chinese literary aesthetics in the new era through reviewing the time points and historical achievements of practical aesthetics in the new era.

\section{PRACTICAL AESTHETICS AND RESTART OF ENLIGHTENMENT MODERNITY}

The 1980s was not only the era of ideological emancipation, but also the "golden age" in which Chinese aesthetics produced extensive and far-reaching social influences exceeding the scope of the discipline. Until today, the aesthetic theorists who experienced the "upsurge in aesthetics" of the year and the younger students under their influence still remember the glory and dreams in that era, and try to reconstruct the lively scene of the year under the strong atmosphere of modern nostalgia in order to alleviate the anxiety of the discipline that is currently struggling and failing to advance and retreat. It should be acknowledged that it is this feeling and the historical narrative under it that made the aesthetics of the $1980 \mathrm{~s}$ still in our sight. However, this historical narrative that has not gone far inadvertently obscured a certain aspect of history while offering insights for us. In order to uncover the obscured aspect, we will return to the historical context of the problem, not only to explore the background of the generation of aesthetic discourse in this period and its development in the process of communication, 
but also to further explore the discourse network weaving this set of aesthetic discourses and the discourse network spread out by this set of aesthetic discourses.

From today's point of view, the ideological emancipation movement in the new era was characterized by the new enlightenment, which has at least two levels of meaning: one is the process of liberating "people's thoughts", and the other is the process by which people get liberated through thinking (used as the verb here). It is in this sense that we believe that "practical aesthetics is the product of the practice of aesthetic thoughts" [1]. In other words, the logical chain should be that the ideological emancipation movement pushed aesthetics to the center of the era stage, and the most important manifestation of the "upsurge in aesthetics" is the formation of the mainstream schools of thought, and the sign of the formation of a school is to have a representative figure who has founded the school and a set of theoretical claims that are believed by the members of the school, and this set of theoretical claims must be embodied in a discourse expression system that is different from the predecessors' and others', and the producer of this set of more glamorous theories will be recognized as the founder and representative figure of this school. Following this logic, Mr. Li Zehou, who has a broad vision and profound academic knowledge, condensed his longterm thinking results into subjective practical philosophy, and this set of abstract philosophical theories developed into the practical aesthetics when applied to the less abstract aesthetic field. Obviously, the practical aesthetic discourse that emphasizes "human subjectivity" was more novel than the reflection theory aesthetics (represented by Mr. Cai Yi et al) born out of classical epistemological philosophy, thus quickly capturing a large number of young students who were trying hard to find ways of expression, so the aesthetic school with the label of practical aesthetics was formed, and the cornerstone of the practical aesthetic discourse building is the word "practice". So what is practice? What can people do in practice? The key noun of "practice" in Marxist philosophy was reinterpreted by $\mathrm{Li}$ Zehou et al as human subjective activities, while subjectivity was regarded as "human selfconfirmation" [2] and further interpreted as the core of modernity. The new era is the period in which China builds modernization and restarts modernity.

Through the overall analysis of the ideological ecology at that time, we can draw the following conclusions. First, the root cause of the "upsurge in aesthetics" is not within the academic knowledge, but in the surging external world, people used aesthetics to express attitudes toward history, standpoints to the reality, and to imagine future resources. Therefore, this kind of upsurge is just an over-upsurge or a virtual upsurge, lacking internal solid support. It also means that although this phenomenon is gorgeous and fascinating, it is unsustainable. With the transformation of the external environment, aesthetics will return to its original peace state. Second, why could practical aesthetics stand out in the aesthetic schools of the new era and surpass other schools in one fell swoop? In addition to the excellent language expressions of the school founder, the fundamental reason is that the core content advocated by this set of discourse - subjectivity was in severe shortage in that era. In view of this, to understand the new enlightenment movement with time continuity and spatial scale, we must grasp the flow of thoughts in practical aesthetics; to dissect the ways of thinking and value orientation of practical aesthetics, we must research Mr. Li Zehou's thought reserve and speech strategies, and this may be the significance of today's discussions on "what to think", "why to think" and "how to think" of Mr. Li's subjective practical aesthetics which was based on the "anthropological ontology" .

\section{THE IMPACT OF PERCEPTUAL MODERNITY ON PRACTICAL AESTHETICS}

In the 1990s, the tide of the market economy surged, people's interest changed, the attention of people turned from the metaphysical thoughts and prospects to the practical surrounding economic situation. Correspondingly, the mass media culture that was not coincident with the refined taste previously is squeezing the elegant art of elite taste nowadays, and the perceptual modernity that promotes the desire for consumption is gradually replacing the enlightenment modernity that emphasizes the rational spirit. Can practical aesthetics and the ideological resources that can be invoked effectively respond to the questions raised by the times? And can this response turn the theoretical crisis into a turn of thoughts? Before discussing this issue, let's first analyze the theoretical embarrassment of practical aesthetics.

As mentioned above, the reason why practical aesthetics could obtain discourse dominance lies not in the degree of exquisiteness of its own theories, but in the concert of its core keyword "practice" and the "practice is the only criterion for testing truth", thus expanding the influence scope and penetration of the theory. Then, in addition to the grand exposition, in the face of meticulous aesthetic experience and aesthetic text, how much could practical aesthetics interpret them? The "tiny times" after the "great times" may need the latter more. Regrettably, practical aesthetics seemed to be incompetent for this work as a kind of grand discourse. All it could do was to continue to invoke the "alienation" theory in Western Marxist, criticize the "commodity fetishism" of the mass consumption society, sigh that the general public was hypnotized by the standardized, commercialized, flat media culture, and take aesthetic activities as the transcendence path to resist the alienation of reality. Of course, this kind of theoretical reflection and criticism contained profound insights, warning us to maintain the vigilance of the consumer culture. This was undoubtedly worthy of recognition, but the problem was that this could only find out the problems, but could not solve them. When the negative effects of capital affecting art and "the commercialization of art" are well known to the public, the fierce and simple aesthetic criticism will become more pale and inadequate. In addition, the criticism for the popular aesthetic culture by the practical aestheticians who had retreated into the ivory tower continued the traditional aesthetic taste of the elites. This kind of lofty and rational attitude of elites that overlooks the sentient beings seems to be so out of place in the era of populist and desire-oriented entertainment and consumption. Therefore, the connecting channel between practical aesthetics and the public space has been obstructed. Classical aesthetics has also retreated from the center to the edge because it is difficult for it to explain the post-modern consumer culture. The estheticians who were 
unwilling to retreat but unable to change the situation could only refine their ideas in the colleges, and this seemed to be regarded by the public as an academic language game that was self-entertaining and incompetent.

\section{THE DiversifIED AESTHETIC SCENEs After THE Practical AEsthetics}

As previously discussed, in the "post-new era" at the turn of the 21 st century, the once-glorious practical aesthetics had transformed from a public discourse that was self-confident, open, and involved in reality into a set of academic discourse that was self-circulating and self-revolving. Even so, in the competition in the internal academic discourse system, the practical aesthetics that had lost the innovation energy and stagnated was increasingly challenged by the rising and popular "post-practical aesthetics" [3], and it had to share academic space and academic discourse power with these rising aesthetic schools.

The term "post-practical aesthetics" comes from the article "Towards Post-Practical Aesthetics" by my mentor, Professor Yang Chunshi. According to his interpretation of this selfnaming, adding the word "post" in front of "practical aesthetics" as a prefix is not just for the distinction of sequence in the sense of time. It also implies their ambition to transcend practical aesthetics and update the aesthetic discourse system. As a loose and heterogeneous school group, "post-practical aesthetics" is mainly evolved from the internal of practice aesthetics, and it can be further subdivided into several schools, such as Mr. Yang Chunshi's transcendence aesthetics, Zhang Hong' s existence aesthetics, Pan Zhichang's life aesthetics, Wang Yichuan's rhetoric aesthetics and so on. The academic resources they quoted are different, and their discourse expressions are also different. The reason why they can share the same title together is that they all think that practical aesthetics is an object that has been "outdated" and needs to be surpassed. The reason for this thought is that the "old practical aesthetics" and its latest development form of the "new practical aesthetics" (represented by Deng Xiaomang, Yi Zhongtian, Zhang Yuneng, etc.) cannot effectively explain the basic issues of aesthetics and art that are still unresolved, and are unable to respond to the ever-changing aesthetic culture phenomenon. As some commentators have pointed out, the reduction of the power of practical aesthetics is the result of the changing of times, rather than the result of consultations with the post-practical aesthetics. And in a certain sense, it is precisely because of the constant attention and regular criticism of post-practical aesthetics that the increasingly backward practical aesthetics can maintain its attention rate and sense of existence in the Chinese language academic field that pursues innovations and advocates advancements with the times. This kind of argument is obviously quite reasonable. The debate between the old and new practical aesthetics and the post-practical aesthetics is long-lasting and still continuing until today. It has not only formed the third great aesthetic discussions in new China, but also caused the diversified development pattern that constitutes today's Chinese aesthetics.

It goes without saying that practice, as the cornerstone of practical aesthetics, inevitably becomes the object that the post-practical aesthetics wants to transcend, because the latter knows that once this cornerstone is taken away, the entire discourse system of practical aesthetics will be shaken and even disintegrated. As we all know, practice is a vague term with rich connotations and broad extensions, so that from ancient Greece to postmodern, many theorists have made different and even opposite interpretations of it according to their needs. Specific to Li Zehou himself, his interpretation of the word "practice" represents the classical expression of this concept by the Chinese language academic community, which is to interpret human subjective practical activities as the "objectivity of human essential power" [4], and to regard it as the nature and root of beauty and art. However, in the view of post-practical aesthetics, no matter how the practical estheticians varnish their theories, "the practical categories with the theory characters of rationality, collectiveness, materiality and realizability are difficult to explain the irrationality, individuality, spirituality and surreality of human art activities (models of aesthetic activities)"[5].

\section{CONCLUSION}

It is worth noting that the construction of the system info of post-practical aesthetics itself is also a process of continuous deepening, reflecting the efforts of Chinese scholars to integrate the past and the present ideas, master Chinese and foreign cultures, reinterpret human art activities, and reconstruct the Chinese aesthetics discourse system in the postmodern cultural context. After a long period of exploration, the post-practical aesthetics, which has been using modernity as the reflection framework, finally found the key concept of intersubjectivity to reflect the practical aesthetics and establish contemporary aesthetics from the phenomenological master Husserl at the beginning of the 21st century [6]. Mr. Yang Chunshi has used the "five transcendence" to summarize the aesthetic discourse system he created, that is, "transcend the substantive existence philosophy and the 'post-metaphysics", establish the ontological aesthetics; transcend the transcendental phenomenology and hermeneutics, and establish the aesthetic phenomenology; transcend the essentialism and deconstruction, establish the intersubjectivity of aesthetics; and transcend the aesthetics of consciousness and body aesthetics, establish the aesthetics of experience" [7]. Obviously, this discourse system of Mr. Yang Chunshi is not only a transcendence of practical aesthetics, but also a transcendence of his original aesthetic thoughts, helping to promote the formation of the "Chinese Schools" in aesthetic research.

\section{REFERENCES}

[1] Wang Wei. Characterizing China: Re-visiting the modernity of the left wing reportage movement [J]. Journal of Quanzhou Normal University, 2013(1): pp.42-46.

[2] Yang Chunshi. Towards the post-practical aesthetics [M]. Hefei: Anhui Education Press, 2008: p81.

[3] Yang Chunshi. Questioning the "Questions for Post-Practical Aesthetics" [J]. Philosophical Trends, 2001 (1): pp.36-38.

[4] Li Zehou. Three monographs in Aesthetics[M]. Hefei: Anhui Literature and Art Publishing House, 1999: p485.

[5] Yang Chunshi, Ren Tian. Seeking Truth from Beyond Self - Interview with Professor Yang Chunshi[J]. Academic Monthly, 2004 (3): pp.97104. 
[6] Yang Chunshi. Intersubjectivity and aesthetic construction in different fields [J]. A Multidimensional Study of Orientalism, 2006 (1): pp.65-74.

[7] Yang Chunshi. The first philosophy-Aesthetics[M]. Beijing: People's Publishing House, 2015: p1. 